\title{
Changes of gene expression profiles across different phases of vascular calcification in rats
}

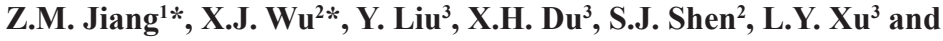 \\ W.X. Sun ${ }^{3}$ \\ 'Department of Anesthesia, Shaoxing People's Hospital of Zhejiang Province, \\ Shaoxing, China \\ ${ }^{2}$ Department of Nephrology, Shaoxing People's Hospital of Zhejiang Province, \\ Shaoxing, China \\ ${ }^{3}$ Department of Nephrology, \\ The First Affiliated Hospital of Wenzhou Medical College, Wenzhou, China \\ *These authors contributed equally to this study. \\ Corresponding author: Y. Liu \\ E-mail: yiliucn@126.com
}

Genet. Mol. Res. 12 (4): 5945-5957 (2013)

Received October 1, 2012

Accepted April 25, 2013

Published November 26, 2013

DOI http://dx.doi.org/10.4238/2013.November.26.4

\begin{abstract}
This study investigated the alteration of gene expression profiles in order to gain a deeper understanding into the molecular mechanism involved in different processes of vascular calcification (VC). Sprague Dawley (SD) rats were injected with $300,000 \mu \mathrm{g} / \mathrm{kg}$ vitamin $\mathrm{D}_{3}$ and gavaged with $25 \mathrm{mg} / \mathrm{kg}$ nicotine for 8 or 16 weeks to create 8- and 16-week VC calcification groups. Histological analysis and quantification of aortic calcium content were used to determine the severity of vascular calcification. The suppression subtractive hybridization ( $\mathrm{SSH}$ ) method was employed to screen for up and downregulated genes in early and later phases of vascular calcification. Changes in calcium and phosphorus levels in tissue were used as markers of vascular calcification. Quantification of aortic calcium content revealed that vascular calcification might regress over time. In the early
\end{abstract}


phase of vascular calcification, many calcification-promoting genes were upregulated, including ossification, oxidation, and inflammatory genes. In contrast, in later phase of vascular calcification, various calcificationinhibitor genes were highly expressed, including pyrophosphoric acid synthesis genes, glutamate signal peptide-related, reduction activity, and apoptosis regulation genes. The relatively higher expression of calcification-inhibitor genes compared to that of calcification-promoting genes might explain the genetic mechanism leading to the regression of vascular calcification. Therefore, this study provides a genomic basis to facilitate understanding of the molecular mechanism underlying vascular calcification regression.

Key words: Calcification; Gene expression; Hybridizations; Animal models; Reversibility

\section{INTRODUCTION}

Vascular calcification (VC) is highly prevalent in many diseases, especially in metabolic disorders, including end-stage renal disease and diabetes mellitus. Additionally, most individuals above 60 years in age have progressively increased deposits of calcium minerals in their major arteries (Allison et al., 2004). Vascular calcification leads to vessel wall stiffness, which reduces vascular compliance and increases cardiac afterload. Furthermore, calcification results in impairment of cardiovascular hemodynamics, and substantial increases of morbidity and mortality due to hypertension, aortic stenosis and sclerosis, cardiac hypertrophy, and congestive heart failure (Ioannou et al., 2009; Coogan et al., 2011; Azevedo et al., 2012). There are 2 pathological patterns of vascular calcification: intimal and medial calcification. In intimal calcification, hydroxyapatite crystals often collocate with lipid- and cell debris-rich areas showing numerous foam cells and macrophages, whereas medial calcification shows vasculopathy features highly characteristic of type 2 diabetes mellitus (Reaven and Sacks, 2005) and chronic kidney disease (Okuno et al., 2007). Arterial medial calcification has drawn increasing research attention in recent years because of its associations with higher cardiovascular mortality and risk of complications in type 2 diabetes mellitus and end-stage kidney disease. The vitamin D plus nicotine (VDN) model we developed reflects the latter form of vascular calcification only.

The mechanism of vascular calcification has become increasingly clear in recent years and is currently recognized as an active and adjustable biological process that shares many features with embryonic bone formation. Additionally, Bas et al. (2006) showed that vascular calcification reversed in rats after withdrawal of calcitriol administration.

The aim of this study was to shed light on the changes in gene expression profiles across different phases of vascular calcification. Sprague Dawley (SD) rats were injected with $300,000 \mu \mathrm{g} / \mathrm{kg}$ vitamin $\mathrm{D}_{3}$ and gavaged with $25 \mathrm{mg} / \mathrm{kg}$ nicotine for 8 or 16 weeks to create 8 and 16-week VC treatment groups. Histological analysis and quantification of aortic calcium content were used to determine the severity of vascular calcification. The suppression subtractive hybridization (SSH) method was employed to screen for upregulated and downregulated genes in early and later phases of vascular calcification. 


\section{MATERIAL AND METHODS}

\section{Animals}

Thirty-six pathogen-free SD male rats, weighing $240 \pm 20 \mathrm{~g}$, were provided by the animal center of Wenzhou Medical College. This study was carried out in strict accordance with recommendations in the Guide for the Care and Use of Laboratory Animals of the National Institutes of Health. The animal use protocol was reviewed and approved by the Institutional Animal Care and Use Committee (IACUC) of The First Affiliated Hospital of Wenzhou Medical College. Rats were randomly divided into 3 groups: 8-week VC group $(\mathrm{N}=8), 16$-week VC group $(\mathrm{N}=8)$, and control group $(\mathrm{N}=8)$. Rats in the treatment groups ( 8 and 16 week VC) were intramuscularly injected with $300,000 \mu \mathrm{g} / \mathrm{kg}$ vitamin $\mathrm{D}_{3}$ (Sigma, USA) and gavaged with $25 \mathrm{mg} / \mathrm{kg}$ nicotine (Sigma) dissolved in peanut oil. The gavage was repeated after $9 \mathrm{~h}$, whereas rats in the control group were treated with intramuscular injections of saline and gavaged with peanut oil only. Rats in the 8-week VC and control groups were raised for 8 weeks and then executed, while rats in the 16- week VC group were raised for 16 weeks until execution.

\section{Histopathological examination}

After harvesting an aorta sample, a pathological specimen was prepared using H\&E and Von Kossa staining. Histological changes of calcified vascular tissue were observed under an optical microscope. Partial vascular tissues were selected to measure the calcium content of the tissue. Vascular tissues were dried to constant weight (for approximately $24 \mathrm{~h}$ ) in a drying cabinet at $110 \pm 5^{\circ} \mathrm{C}$. After the addition of $\mathrm{HNO}_{3}(\mathrm{v} / \mathrm{v}=67 \%)$, the tissues were boiled to digest and then anchored on an electric hot plate at $200 \pm 10^{\circ} \mathrm{C}$ to dry. The samples were then dissolved in distilled water to a $100 \mathrm{~mL}$ volume, and then quantified in an atomic absorption spectrophotometer.

\section{Suppression subtractive hybridization}

After conventional RNA extraction using the Trizol ${ }^{\mathrm{TM}}$ Reagent (Invitrogen, USA), SSH was performed with the PCR-Select ${ }^{\mathrm{TM}}$ cDNA Subtraction Kit (Clontech, USA), following manufacturer protocols. SSH was carried out between the 8-week VC group and the control group, and between the $2 \mathrm{VC}$ treatment groups. Therefore, 4 subtractive cDNA libraries were constructed and denoted as follows:

VC-f library (forward subtraction): represents genes that are overexpressed during the process of $\mathrm{VC}$ since tissue from the 8-week VC group was used as the tester and tissue from the control group was used as the driver.

VC-r library (reverse subtraction): represents genes expressed at low levels during the process of $\mathrm{VC}$ since tissue from the control group was used as the tester and tissue from the 8 -week VC group was used as the driver.

VCR-f library (forward subtraction): represents genes overexpressed during the process of $\mathrm{VC}$ regression since tissue from the 16-week VC group was used as the tester and tissue from the 8-week VC group was used as the driver. 
VCR-r library (reverse subtraction): represents genes expressed at low levels during the process of $\mathrm{VC}$ regression since tissue from the 8-week VC group was used as the tester and tissue from the 16-week VC group was used as the driver.

For simplification, we consider genes in the VC-f library as those upregulated during the calcification process and genes in the VC-r library as those that are downregulated in the calcification process. The same applies to the VCR library.

\section{SSH-sequence data analysis}

Positive clones were sent to Invitrogen (ShangHai Agent, China) for DNA sequencing. Homology search was performed by matching nucleotide sequences deposited in international public databases using the basic local alignment search tool (BLAST) engine. The non-redundant database branch of GenBank/EMBL/DDBJ and the National Center for Biotechnology Information (http://www.ncbi.nlm.nih.gov/) was used for this analysis.

\section{Reverse transcription PCR (RT-PCR)}

Ten different gene segments were randomly selected, corresponding primer sequences were designed, and the RT-PCR program was set as follows: $94^{\circ} \mathrm{C}$ for $30 \mathrm{~s}, 60^{\circ} \mathrm{C}$ for $45 \mathrm{~s}, 72^{\circ} \mathrm{C}$ for $1 \mathrm{~min}$, and $6 \mathrm{~min}$ at $72^{\circ} \mathrm{C}$.

\section{RESULTS}

\section{Histopathological examination}

As shown in Figure 1, rats in the control group demonstrated normal histologies without calcium deposition and with integral endothelial cells (Figure 1A and B). Rats in the 8-week VC group displayed brown calcium salt deposition along the arterial tunica lamina in a linear manner, with a ruptured local tunica elastic plate and the normal arterial structure dismantled (Figure 1C and D). The rats in the 16-week VC group still showed calcium deposits in the arterial tunica lamina (Figure 1E and F); however, the phenomenon seemed to be less apparent. Additionally, the phagocytes began to adhere to the calcifying foci at 16 weeks (Figure 1G).

\section{Calcium, phosphorus, and alkaline phosphatase (AKP) dynamics}

The levels of calcium, phosphorus, and AKP in the serum and tissue are shown in Table 1. The concentrations of calcium, phosphorus, and AKP in the serum did not differ significantly among the 3 groups (control group, 8- and 16-week VC group). Similarly, the AKP levels in the tissue did not differ significantly among the 3 groups. In contrast, the concentrations of calcium and phosphorus were much higher in the 8-and 16-week $\mathrm{VC}$ groups compared to those of the control group $(\mathrm{P}<0.01)$, which indicated that changes in calcium and phosphorus in the vascular tissues can be used as markers for vascular calcification. 

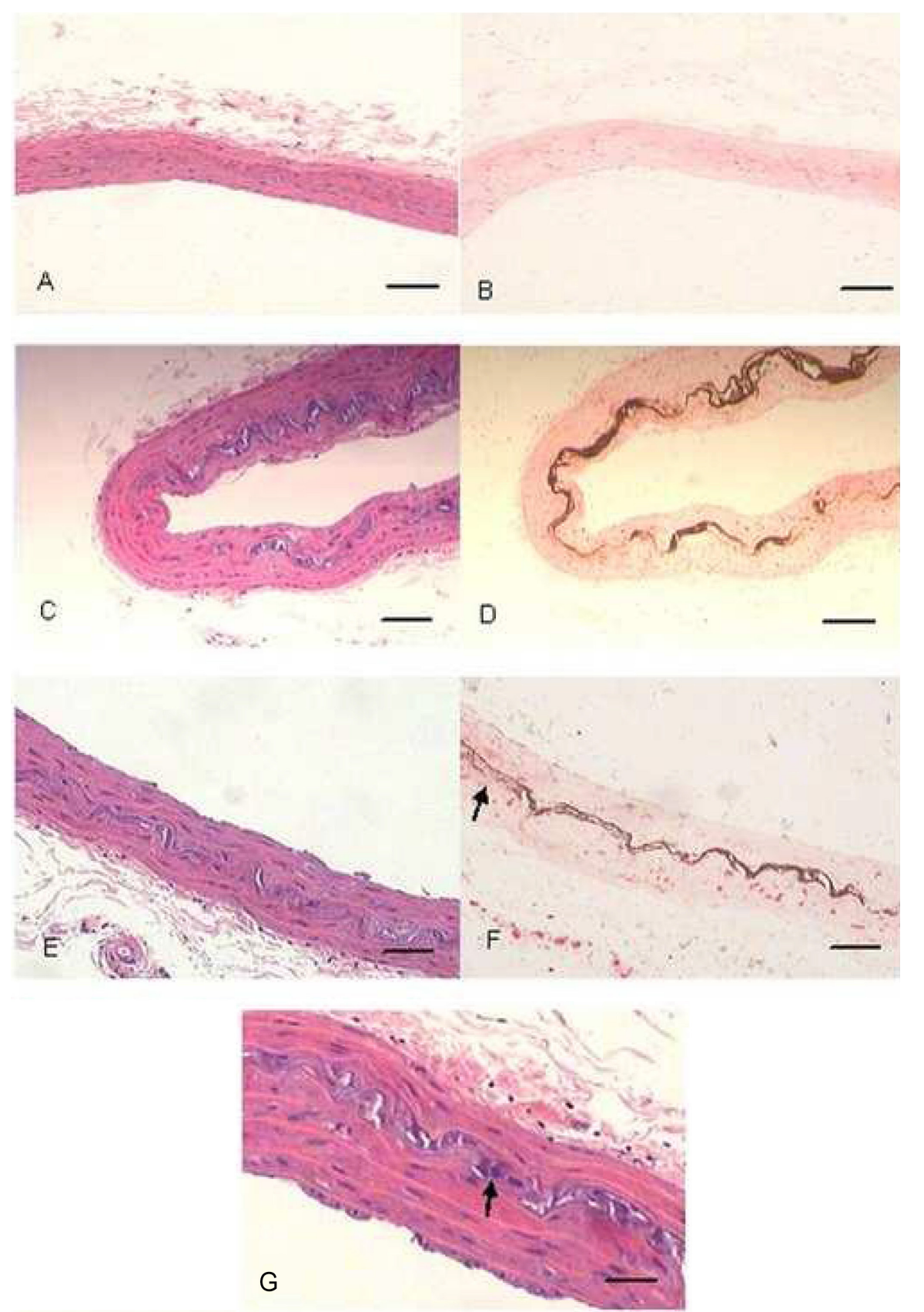

Figure 1. Histopathologic examination of rats' aorta. A. B. C. D. E. F. bar $=50 \mu \mathrm{m}$. G bar $=20 \mu \mathrm{m}$. A. C. E. G. HE stain; B. D. F. Von Kossa stain. (Tissue samples from the abdominal aorta of rats). A. and B. show normal histology of rats' aorta in control group. $\mathbf{C}$ and $\mathbf{D}$ calcium salts deposited in arterial tunica lamina in rats of VC 8 weeks group. E. and F. calcium deposition less apparent (arrows) in VC 16-weeks group compared than that in VC 8-weeks group. G. Phagocytes were adhered to the calcifying foci in rats of VC 16-weeks group (arrows). 
Table 1. Levels of calcium, phosphorus and AKP in serum and tissue.

\begin{tabular}{|c|c|c|c|c|c|c|}
\hline \multirow[t]{2}{*}{ Groups } & \multicolumn{3}{|c|}{ Serum } & \multicolumn{3}{|c|}{ Tissue } \\
\hline & $\mathrm{AKP}(\mathrm{U} / \mathrm{L})$ & Calcium (mg/g) & Phosphorus (mg/g) & $\mathrm{AKP}(\mathrm{U} / \mathrm{L})$ & Calcium (mg/g) & Phosphorus (mg/g) \\
\hline CTRL & $55.67 \pm 2.61$ & $9.24 \pm 0.20$ & $5.09 \pm 0.23$ & $33.38 \pm 5.82$ & $5.20 \pm 0.75$ & $2.57 \pm 0.69$ \\
\hline 8 weeks & $94.19 \pm 3.09$ & $9.39 \pm 0.23$ & $5.21 \pm 0.24$ & $123.1 \pm 10.47$ & $15.34 \pm 2.51^{*}$ & $9.64 \pm 1.54 *$ \\
\hline 16 weeks & $74.71 \pm 3.02$ & $9.39 \pm 0.30$ & $5.10 \pm 0.27$ & $51.85 \pm 8.89$ & $12.73 \pm 1.89^{*}$ & $7.41 \pm 1.03 *$ \\
\hline
\end{tabular}

\section{Subtraction efficiency}

We estimated the efficiency of SSH by comparing the abundance of the rat housekeeping gene, $G 3 P D H$, before and after subtraction after amplification for 20, 25, 30, and 35 cycles. The results (Figure 2) showed that PCR amplification products in subtracted cDNA were significantly decreased compared to those of unsubtracted cDNA in each cycle, which indicated that the efficiency of the subtraction was high.

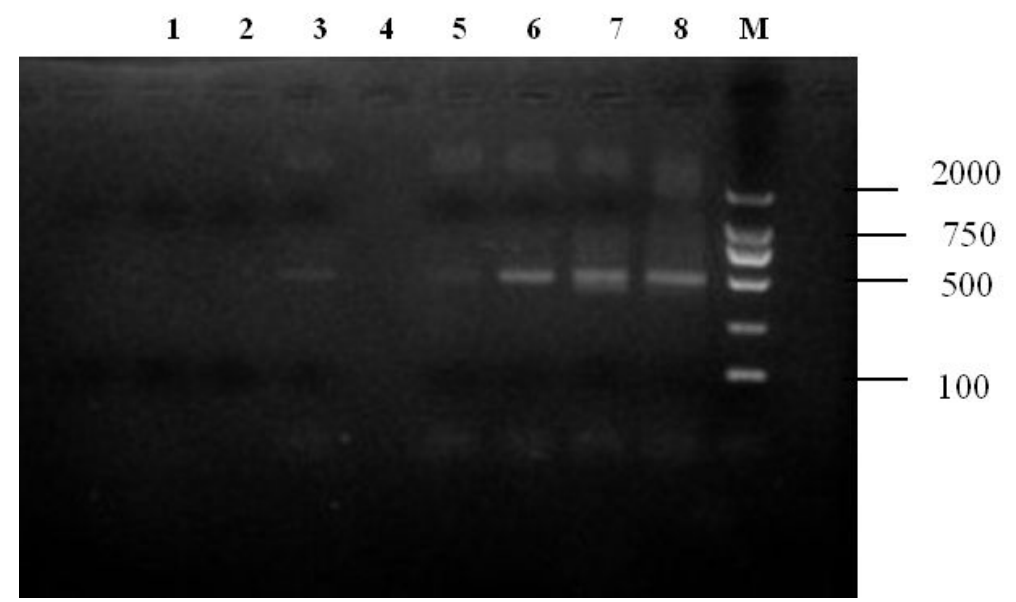

Figure 2. Detection of subtractive hybridization efficiency. PCR was performed on the subtracted. Lanes 1-4 = subtracted cDNA, lanes 5-8 = unsubtracted cDNA secondary PCR product with the G3PDH primers. Lanes 1 and $5=20$ cycles; lanes 2 and $6=25$ cycles; lanes 3 and $7=30$ cycles; lanes 4 and $8=35$ cycles; lane $M=$ marker.

\section{SSH sequence data analysis}

A total of 256 positive clones were detected after colony PCR identification, and the positive rate of cloning was approximately $90 \%$ (256/288). The length of inserted segments ranged from 200 to $350 \mathrm{bp}$ (Figure 3). The results of the BLAST alignment against the gene bank database are displayed in Tables 2 and 3.

\section{RT-PCR}

Differentially expressed genes were demonstrated using RT-PCR analysis, and the re- 
sults showed an average 1.7-fold change. In contrast, the expression of G3PDH in the original corresponding tissues remained stable (Figure 4).

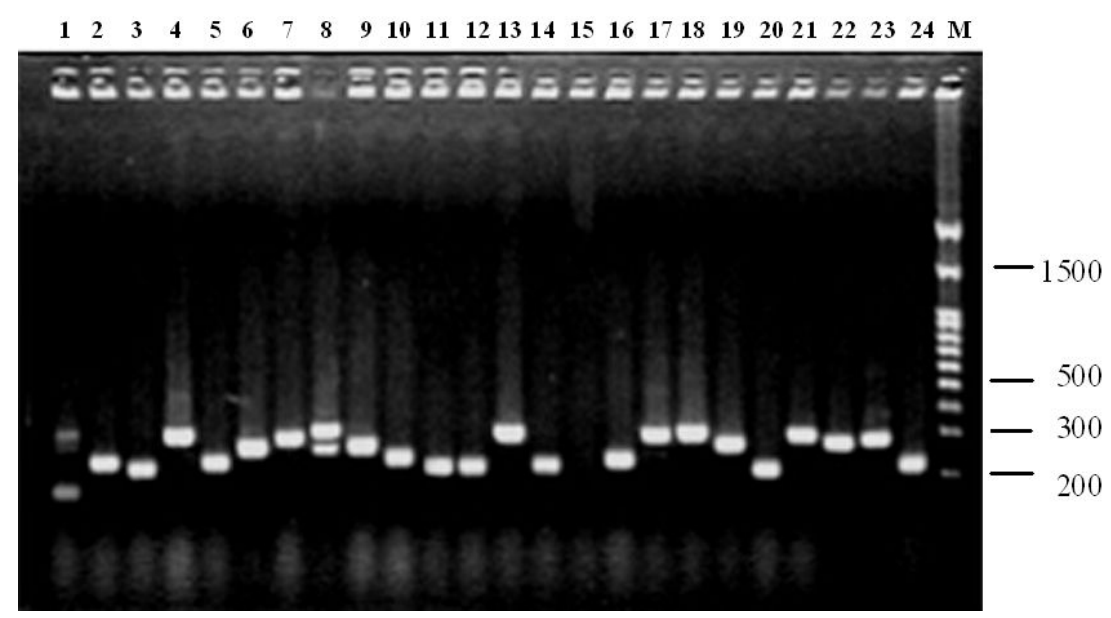

Figure 3. Colony PCR identification. Partial results of colony PCR certification, 23 clones have insert target fragments (positive clones) in 24-well plate, except for the 15 th clone from the left.

Table 2. Up and downregulated genes in calcification progress.

\begin{tabular}{|c|c|c|c|c|c|c|c|}
\hline \multicolumn{4}{|c|}{ Upregulated genes (VC-f library) } & \multicolumn{4}{|c|}{ Downregulated genes (VC-r library) } \\
\hline E value & Homology & $\begin{array}{l}\text { Gene } \\
\text { symbol }\end{array}$ & Protein name & E value & Homology & $\begin{array}{l}\text { Gene } \\
\text { symbol }\end{array}$ & Protein name \\
\hline 0.063 & $88.6 \%$ & $I g f l 3$ & IGF-like family 3 & $2.7 \mathrm{e}-06$ & $91.1 \%$ & Nidl & Nidogen 1 \\
\hline $5.5 \mathrm{e}-17$ & $80.7 \%$ & $\operatorname{Igfbp} 2 / 5$ & $\begin{array}{l}\text { Insulin-like growth factor } \\
\text { binding protein } 2 / 5\end{array}$ & $3.2 \mathrm{e}-27$ & $88.6 \%$ & Atplbl & $\begin{array}{l}\text { ATPase, } \mathrm{Na}^{+} / \mathrm{K}^{+} \\
\text {transporting, beta } 1\end{array}$ \\
\hline $1.7 \mathrm{e}-68$ & $82.1 \%$ & Alpl & $\begin{array}{l}\text { Alkaline phosphatase, } \\
\text { liver/bone/kidney }\end{array}$ & $3.3 \mathrm{e}-05$ & $88.6 \%$ & $\begin{array}{l}\text { Gimap 1/4/ } \\
5 / 6 / 7 / 9 / 19\end{array}$ & $\begin{array}{l}\text { GTPase, IMAP family } \\
\text { Member } 1 / 4 / 5 / 6 / 7 / 9 / 19\end{array}$ \\
\hline $1.3 e-34$ & $83.7 \%$ & Bmp4 & $\begin{array}{l}\text { Bone morphogenetic } \\
\text { protein } 4\end{array}$ & $9.2 \mathrm{e}-05$ & $80.3 \%$ & $S g k 3$ & $\begin{array}{l}\text { Cytokine-independent } \\
\text { survival kinase }\end{array}$ \\
\hline $1.3 e-19$ & $73.7 \%$ & Bmp5 & Bone morphogenetic protein 5 & $2.1 \mathrm{e}-122$ & $100.0 \%$ & Rftn2 & Raftlin family member 2 \\
\hline $1.8 \mathrm{e}-15$ & $95.7 \%$ & Nell1 & NEL-like 1 & $5.4 \mathrm{e}-08$ & $100.0 \%$ & Pdia6 & $\begin{array}{l}\text { Protein disulfide isomerase } \\
\text { family A, member } 6\end{array}$ \\
\hline $3.5 \mathrm{e}-97$ & $96.3 \%$ & Epha4 & Epha4 Eph receptor A4 & $1.1 \mathrm{e}-22$ & $75.8 \%$ & Tnsl & Tensin 1 \\
\hline $2.5 \mathrm{e}-23$ & $84.9 \%$ & Notch4 & Notch homolog 4 & $4.2 \mathrm{e}-28$ & $82.0 \%$ & Thbs 4 & Thrombospondin 4 \\
\hline $1.7 \mathrm{e}-131$ & $98.2 \%$ & Plxna2 & Plexin A2 & $2.1 \mathrm{e}-122$ & $100.0 \%$ & Mars2 & Methiony-tRNA synthetase 2 \\
\hline $5.0 \mathrm{e}-06$ & $91.7 \%$ & $\mathrm{CDH13}$ & Cadherin 13 & $5.8 \mathrm{e}-20$ & $74.5 \%$ & $P d x k$ & $\begin{array}{l}\text { Pyridoxal (pyridoxine, } \\
\text { vitamin B6) kinase }\end{array}$ \\
\hline $1.8 \mathrm{e}-10$ & $92.5 \%$ & Spockl & Osteonectin & & & & \\
\hline $4.1 \mathrm{e}-07$ & $84.2 \%$ & Trip11 & $\begin{array}{l}\text { Thyroid hormone receptor } \\
\text { interactor } 11\end{array}$ & & & & \\
\hline $3.9 \mathrm{e}-10$ & $80.4 \%$ & $F g f 18$ & Fibroblast growth factor 18 & & & & \\
\hline $4.7 e-23$ & $86.4 \%$ & $T g f b r 2$ & $\begin{array}{l}\text { Transforming growth factor, } \\
\text { beta receptor II }\end{array}$ & & & & \\
\hline $2.9 \mathrm{e}-95$ & $99.0 \%$ & $C t g f$ & Connective tissue growth factor & & & & \\
\hline $5.7 e-33$ & $93.6 \%$ & $V d r$ & Vitamin D receptor & & & & \\
\hline $9.3 e-111$ & $90.6 \%$ & Crhr2 & $\begin{array}{l}\text { Corticotropin releasing hormone } \\
\text { receptor } 2\end{array}$ & & & & \\
\hline $3.3 e-49$ & $84.7 \%$ & Ptgfr & Prostaglandin F receptor & & & & \\
\hline $7.7 e-51$ & $85.2 \%$ & Mpa2l & Macrophage activation 2 like & & & & \\
\hline $9.9 \mathrm{e}-20$ & $96.8 \%$ & Il4 & Interleukin 4 & & & & \\
\hline $9.9 \mathrm{e}-20$ & $96.8 \%$ & $I l 13$ & Interleukin 13 & & & & \\
\hline
\end{tabular}

VC-f library $=8$-week VC group used as a tester and control group as a driver. VC-r library = control group used as a tester and 8-week VC group as a driver. 
Table 3. Up and downregulated genes in vascular calcification regression.

\begin{tabular}{|c|c|c|c|c|c|c|c|}
\hline \multicolumn{4}{|c|}{ Upregulated genes (VCR-f library) } & \multicolumn{4}{|c|}{ Downregulated genes (VCR-r library) } \\
\hline E value & Homology & Gene & Gene products & E value & Homology & Gene & Gene products \\
\hline \multirow[t]{2}{*}{$2.9 \mathrm{e}-95$} & $99.0 \%$ & Enppl & Ectonucleotide pyrophosphatase/ & $1.7 \mathrm{e}-68$ & $82.2 \%$ & Bmpl5 & Bone morphogenetic protein 15 \\
\hline & & (/3) & Phosphodiesterase 1(/3) & $1.7 \mathrm{e}-68$ & $82.1 \%$ & Alpl & Alkaline phosphatase \\
\hline \multirow[t]{2}{*}{$5.6 e-31$} & $91.8 \%$ & Prps 2 & $\begin{array}{l}\text { Phosphoribosyl pyrophosphate } \\
\text { Synthetase } 2\end{array}$ & $2.1 \mathrm{e}-46$ & $99.1 \%$ & Colla2 & Collagen, type I, alpha 2 \\
\hline & & & & $2.6 \mathrm{e}-45$ & $78.0 \%$ & $T g f b l$ & Transforming growth factor, $\beta 1$ \\
\hline $4.7 \mathrm{e}-17$ & $98.2 \%$ & Ank2 & Ankyrin 2 & $5.0 \mathrm{e}-48$ & $99.1 \%$ & Cyp2lal & $\begin{array}{l}\text { Cytochrome } \mathrm{P} 450 \text {, subfamily } 21 \mathrm{~A} \\
\text { polypeptide } 1\end{array}$ \\
\hline $3.2 \mathrm{e}-27$ & $79.0 \%$ & Atplbl & ATPase $\mathrm{Na}^{+} / \mathrm{K}^{+}$transporting & & & & \\
\hline \multirow[t]{2}{*}{$5.7 \mathrm{e}-34$} & $78.9 \%$ & $A b c c l$ & ATP-binding cassette, sub-family $\mathrm{C} 1$ & $7.9 \mathrm{e}-33$ & $93.9 \%$ & $K c p$ & Kielin/chordin-like protein \\
\hline & & & & $1.3 \mathrm{e}-36$ & $94.4 \%$ & Slc25a22 & Solute carrier family 25 \\
\hline $5 e-14$ & $84.1 \%$ & Pak7 & $\begin{array}{l}\text { p21 protein }(\mathrm{Cdc} 42 / \mathrm{Rac})- \\
\text { activated kinase } 7\end{array}$ & $7.1 \mathrm{e}-67$ & $81.1 \%$ & Fhit & $\begin{array}{l}\text { Diadenosine triphosphate } \\
\text { hydrolase (Fhit) }\end{array}$ \\
\hline $1.6 \mathrm{e}-05$ & $82.1 \%$ & $\operatorname{Tx} n 2$ & Thioredoxin 2 & $7.9 \mathrm{e}-33$ & $93.9 \%$ & Calu & Calumenin \\
\hline $1.1 \mathrm{e}-67$ & $89.1 \%$ & Gsta3 & Glutathione S-transferase A3 & $8.7 \mathrm{e}-66$ & $80.8 \%$ & Smad 9 & MAD homolog 9 \\
\hline $4.1 \mathrm{e}-17$ & $98.2 \%$ & $\operatorname{Prdx} 3$ & Peroxiredoxin 3 & $1.6 \mathrm{e}-98$ & $85.9 \%$ & Prkd3 & Protein kinase D3 \\
\hline $4.1 \mathrm{e}-17$ & $98.2 \%$ & $\operatorname{Prdx} 6$ & Peroxiredoxin 6 & $2.8 \mathrm{e}-51$ & $78.3 \%$ & $P d e 8 b$ & Phosphodiesterase 8B \\
\hline $4.1 \mathrm{e}-42$ & $82.2 \%$ & Uqcrfs 1 & Ubiquinol-cytochrome $\mathrm{c}$ reductase & $5.0 \mathrm{e}-48$ & $99.1 \%$ & $\begin{array}{l}\text { Btnl6 } \\
(7 / 8 / 9)\end{array}$ & Butyrophilin-like $6(7 / 8 / 9)$ \\
\hline $1.4 \mathrm{e}-14$ & $85.5 \%$ & Cbrl & Carbonyl reductase 1 & $1.7 \mathrm{e}-34$ & $92.2 \%$ & Ccdc25 & Coiled-coil domain containing 25 \\
\hline $5.2 \mathrm{e}-64$ & $82.1 \%$ & Esrl & Estrogen receptor 1 (alpha) & $4.4 \mathrm{e}-15$ & $76.6 \%$ & Lox12 & Lysyl oxidase-like 2 \\
\hline 0.0015 & $85.7 \%$ & Aatf & $\begin{array}{l}\text { Apoptosis antagonizing } \\
\text { transcription factor }\end{array}$ & $1.6 \mathrm{e}-98$ & $85.9 \%$ & Eif $2 a k 2$ & $\begin{array}{l}\text { Eukaryotic translation initiation } \\
\text { Factor 2-alpha kinase } 2\end{array}$ \\
\hline $2.5 \mathrm{e}-14$ & $84.1 \%$ & $\operatorname{Itg} b 3 b p$ & Integrin beta 3 binding protein & $7.9 \mathrm{e}-33$ & $93.9 \%$ & $\operatorname{Irf} 5$ & Interferon regulatory factor 5 \\
\hline $4.7 \mathrm{e}-17$ & $98.2 \%$ & Prrgl & Proline rich Gla 1 & $2.6 \mathrm{e}-45$ & $78.0 \%$ & Axl & AXL receptor tyrosine kinase \\
\hline $2.1 \mathrm{e}-12$ & $81.9 \%$ & Prrg4 & Proline rich Gla 4 & $5.0 \mathrm{e}-48$ & $99.1 \%$ & Notch4 & Notch homolog 4 \\
\hline $1.4 \mathrm{e}-11$ & $88.3 \%$ & Il9r & Interleukin 9 receptor & & & & \\
\hline 0.0001 & $100.0 \%$ & $\operatorname{Adm} 2$ & Adrenomedullin 2 & & & & \\
\hline $5.9 \mathrm{e}-76$ & $77.8 \%$ & Grm7 & Glutamate receptor, metabotropic 7 & & & & \\
\hline $7.0 \mathrm{e}-29$ & $89.5 \%$ & Grm8 & Glutamate receptor, metabotropic 8 & & & & \\
\hline $5.0 \mathrm{e}-102$ & $77.8 \%$ & $S 100 a$ & S100 calcium binding protein A & & & & \\
\hline $3.9 \mathrm{e}-10$ & $80.4 \%$ & $F g f 18$ & Fibroblast growth factor 18 & & & & \\
\hline $4.1 \mathrm{e}-05$ & $85.4 \%$ & Angptl & Angiopoietin 1 & & & & \\
\hline $5.5 \mathrm{e}-89$ & $75.0 \%$ & Thsd7a & Thrombospondin, type I & & & & \\
\hline $3.3 \mathrm{e}-05$ & $84.3 \%$ & Casp14 & Caspase 14 & & & & \\
\hline $3.1 \mathrm{e}-37$ & $80.4 \%$ & $C t s b$ & Cathepsin B & & & & \\
\hline $8.8 \mathrm{e}-64$ & $87.6 \%$ & Ggps 1 & $\begin{array}{l}\text { Geranylgeranyl diphosphate } \\
\text { synthase } 1\end{array}$ & & & & \\
\hline $3.5 \mathrm{e}-14$ & $80.2 \%$ & Nenf & Neuron derived neurotrophic factor & & & & \\
\hline
\end{tabular}

VCR-f library: used VC 16-week group as a tester and VC 8-week group as a driver to get up-expressed genes. VCR-r library: used VC 8-week group as a tester and VC 16-week group as a driver to get down-expressed genes.

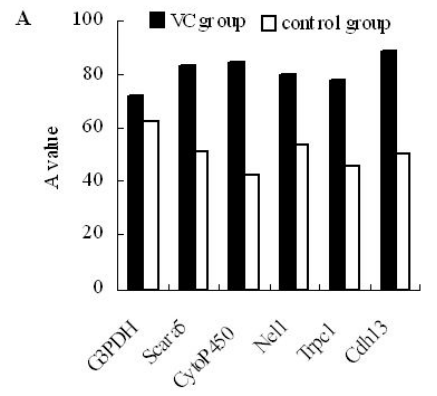

gene

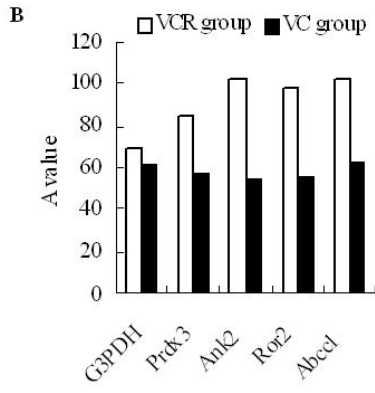

gene

Figure 4. RT-PCR verification and DNA bands of semi-quantitative analysis. Horizontal axis denoted housekeeping gene (the 1st gene from the left) and randomly selected certification genes (except the 1st gene). FC $=$ fold change of gene expression (VC 8-week group over control group or VC 16-week group over VC 8-week group). FC G3PDH=1.14; FC Scara5 = 1.65; FC CytoP450=1.97; FC Nel1 = 1.47; FC Trpc1 = 1.71; FC Cdh13 $=1.76 ; \mathrm{FC} \operatorname{Prdx} 3=1.50 ; \mathrm{FC} A n k 2=1.89 ; \mathrm{FC} \mathrm{Ror2}=1.78 ; \mathrm{FC} A b c c 1=1.63$. 


\section{DISCUSSION}

This article globally describes variations in gene expression of VDN rats across different phases of vascular calcification, with the aim to clarify the molecular mechanisms involved in the process. Our pathological findings and quantification of calcium and phosphorus contents showed that the VDN rat models were successfully constructed. Additionally, vascular calcification was also demonstrated to regress over time, which is similar to results of previous studies (Allison et al., 2004). A total of 121 genes were obtained through sequencing and BLAST analysis. Among these genes, 7.4\% were found in both tissue libraries and were discarded as they reflected false positives. Therefore, 59 genes related to the process of $\mathrm{VC}$ formation, and 53 genes related to the process of $\mathrm{VC}$ regression were identified, $40 \%$ of which presented more than once in the matching analysis. Given that subjectivity exists to some degree in the process of BLAST alignment, at least 2 researchers independently focused on the transcripts to minimize the possibility of false positives and subjectivity. To verify differentially expressed SSH genes in the original vascular tissue, we subjected a subsample to RT-PCR and semi-quantitative band analysis.

Although few common genes were detected among the 4 libraries observed, some relationships were nonetheless evident. Some genes with similar functions, or genes belonging to the same superfamily, were upregulated during the calcification phase, but were downregulated or lost during the regression phase. For example, the genes Bmp-4 and Bmp-5 were upregulated in the VC-f library, and Bmp-15 was downregulated in the VCR-r library. Similarly, some related genes were upregulated during calcification regression, but downregulated or lost in the calcification progression. For example, the gene Atp6v0e2 was upregulated in the VC-r library, and the gene Atp1b1 was downregulated in the VCR-f library. Similarly, the gene Thbs 4 was upregulated in the VC-r library, and the gene Thsd7a was downregulated in the VCR-f library; however, Itgb3bp appeared in both the VC-r and VCR-f libraries.

We also found many genes with opposite functions in the VC-f library (increased gene expression during VC formation) and in the VCR-f library (increased gene expression during VC regression): the antioxidant activity genes $C y p 4 f 18, m t-C o 3$, and $F m o 9$ in the VC-f library, and $\operatorname{Prdx}$ 3, Uqcrfs 1, and Cbrl in the VCR-f library; the apoptosis-inducing genes $P d c d 1$ and $M e f 2 c$ in the VC-f library, and Aatf, Itgb3bp, Pak7, and Il9r in the VCR-f library; the ATP synthesis and ATPase inhibitor genes $A D K$ and Pln in the VC-f library, and the ATPase activity genes Atplb1 and $A b c c 1$ in the VCR-f library. All of these results were consistent with the working principle of $\mathrm{SSH}$ and the biological process of calcification and regression, indicating that oxidation, apoptosis, and ATP synthesis contribute to vascular calcification formation, while anti-oxidation, antiapoptosis, and ATP reduction favor regression of vascular calcification.

Another distinctive feature of note was that many ossification genes were found to be upregulated in the VC-f library. Recently, similarities between vascular calcification and bone metabolism have been recognized. Vascular calcification is closely related to ossification as the endothelial and mesenchymal cells interact with osteotropic hormones and morphogenetic signals governing skeletal mineralization, their counterparts in governing arterial mineralization (Towler and Demer, 2011).

In response to oxidative stress, inflammatory, metabolic, and morphogenetic signals, dystrophic calcium deposition occurs in partially dying vascular smooth muscle cells (VSMCs), the ossification processes is activated, and the VSMCs become activated and 
are prone to convert to osteoblasts or cartilage cells (Okamoto et al., 2012). Given that $I G F-I$ and $B M P S$ have been demonstrated to play significant roles in calcification, much attention has recently focused on newly-found genes related to calcification in subtractive libraries, such as Nell-1 and Cdh13. Nell-1 (encoding NEL-like1) and Cdh13 (encoding cadherin $13 / \mathrm{H}$-cadherin) are regarded as early expressed genes during the process of ossification. Nell-1 is thought to specifically target cells of the osteogenic lineage, and is able to stimulate osteogenic differentiation to regenerate bone in vivo. Nell-1 accelerates bone regeneration through accelerating mineralization via increased inorganic phosphate $(\mathrm{Pi})$ transportation and increased extracellular matrix protein production ( $\mathrm{Li}$ et al., 2011). Cdh13 is primarily considered to be an anti-oncogene (Qian et al., 2007), although some studies have demonstrated that it is substantially expressed in the process of ossification. Some other genes, including Epha4, Notch4, Spock1, and Mef2c, have also been related to ossification (Cozzolino et al., 2001; Arnold et al., 2007; Kuroda et al., 2008; Shimizu et al., 2011). All of these genes were differentially expressed in the subtractive library of vascular calcification, which indicated partially identical biological characteristics to the ossification process. Consequently, mechanisms of ossification significantly affected the process of calcification.

Apart from ossification, genes related to cell apoptosis, inflammation reaction, and oxidative stress were also involved in calcification, although their final common pathway appeared to be destined to ossification. The genes $P d c d 1$ and $M e f 2 c$ could induce apoptosis, and several studies have demonstrated that the apoptosis bodies derived from VSMCs could initiate calcification in a similar manner to chondrocyte matrix vesicles (Proudfoot et al., 2000; Reynolds et al., 2004; Chasseraud et al., 2011; Kapustin et al., 2011). The inflammation factors IL-2, IL-4, and IL-13 appeared in the VC-f library, and IL-9 appeared in the VCR-f library. However, this did not necessarily indicate that non-specific inflammation played a role in vascular calcification, because some inflammation factors also showed close relationships with ossification, and they can regulate ossification by working with bone-regulated proteins (Bennett et al., 2006; Morony et al., 2008). Many genes related to vascular calcification were sensitive to oxidative stress. Oxidases, including cytochrome C oxidase III (encoded by $m t-C o 3$ ), can increase oxidative stress production (particularly $\mathrm{H}_{2} \mathrm{O}_{2}$ ). A recent study demonstrated that increased generation of reactive oxygen species was predominately located around calcifying foci, which facilitated the formation of vascular calcification. Activation of PI3K/AKT signaling appeared to mediate oxidative stress-induced Runx2 expression, and the latter was essential for VSMCs to differentiate into osteoblasts (Byon et al., 2008).

A comparison of gene function and location of the VCR-f and VCR-r libraries in regression tissue is shown in Figure 5. During the process of calcification regression, the expressions of anti-apoptosis and antioxidant genes increased, whereas genes related to pyrophosphoric acid (PPi) synthesis, glutamate signaling, and ATPase were highly inhibited.

Ectonucleotide pyrophosphatase/phosphodiesterase1(/3) and phosphoribosyl pyrophosphate synthetase 2, encoded by the genes Enpp1(/3)and Prps2, respectively, were the main generators of inorganic PPi in the vascular tissue. PPi inhibits vascular calcification by preventing the deposition of calcium and phosphorus into calcium phosphate crystals. In addition, PPi also functions to stabilize the phenotype of aortic VSMCs, and a reduction of PPi might therefore induce VSMCs to change into a chondrocyte or osteoblast-like cell (Johnson et al., 2005). Ankyrin-2, which is encoded by Ank2, is a pyrophosphate transporter that inhibits calcium and phosphorus deposition at the extracellular matrix by transporting PPi from the intracellular to the extracellular space. 


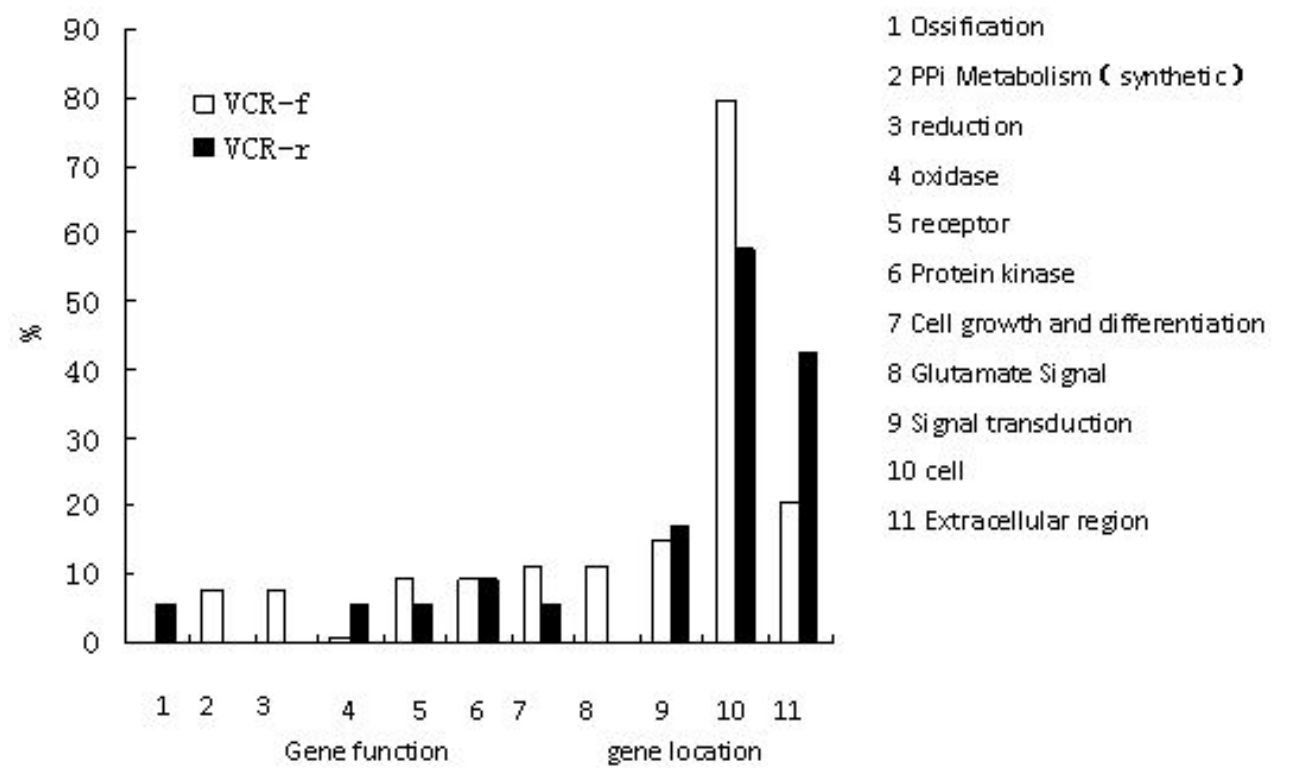

Figure 5. Comparison of gene function and location of VCR-f and VCR-r libraries. VCR-f = forward library contains upregulated genes in $\mathrm{VC}$ regression tissue; VCR-r $=$ reverse library contains downregulated genes in $\mathrm{VC}$ regression tissue.

Recent evidence has revealed that both glutamate and its receptor function in non-neuronal tissues, such as bone, pancreas, and skin. Glutamate is converted into $\gamma$-carboxyglutamic acid (Gla) through the addition of an extra carboxyl group, which is catalyzed by a vitamin K-dependent carboxylase. Gla has a high affinity with hydroxyapatite to inhibit calcium deposition and the growth of hydroxyapatite crystals. The matrix-Gla protein is well known to act as a strong inhibitor of vascular calcification, and it contains no more than 5 Gla-residue functional groups. Glutamate also plays an important role in cellular development through its interaction with Group III metabotropic glutamate receptors (group III mGluRs). Group III mGluRs have been shown to be expressed in chondrocytes as well as in osteoblasts, and can almost completely inhibit chondral mineralization in the presence of the group III mGluR agonist, L-AP4 (Liyang et al., 2005). This is most likely due to the ability of group III mGluR subtypes to inhibit the formation of cAMP through a Gi protein negatively linking to adenylyl cyclase. Therefore, decreased intracellular cAMP levels following changes in ion channels and cytokine secretion might be at least partially responsible for the suppression of chondral mineralization.

In our study, Prrg1 and Prrg4, encoding proline rich Gla protein 1 and 4, respectively, were present in the VCR-f library. Grm 7 and Grm8, encoding the glutamate receptors, metabotropic 7 and 8 , respectively. The fact that these genes were present in the subtractive libraries implied that glutamatergic signaling likely plays an important role in regulating vascular calcification via a mechanism similar to that regulating bone and cartilage mineralization.

ATPase encoding genes (Atplb1), and genes with similar functions (e.g., Abccl and Pak7) were upregulated in the VCR-f library, and were downregulated in the VC-r library, which indicated that ATPase could accelerate the process of $\mathrm{VC}$ regression. Results of a recent 
study indicated that ATP could affect the mineral type formed in matrix vesicles to produce effectors of mineralization, stimulatory inorganic phosphate, or inhibitory inorganic pyrophosphate. ATPase could also directly inhibit calcification induced by ATP (van der Windt et al., 2012). Therefore, the PPi generated through decomposition of the corresponding substrate by ATPase could also inhibit vascular calcification.

\section{CONCLUSION}

In the present study, differentially expressed genes were found during the processes of vascular calcification formation and regression. These results indicated that the process of vascular calcification regresses when calcification inducers are eliminated from the environment. The upregulation of relevant calcium regression genes appeared to play an important role in this process. Together, these results provide a genomic basis to facilitate understanding of the molecular mechanisms involved in vascular calcification regression.

\section{ACKNOWLEDGEMENTS}

Research supported by the Zhejiang Provincial Natural Science Foundation of China (\#Y207493). We are also grateful to The Shanghai Institutes for Biological Sciences and the ChaShan campus of WenZhou Medical College for providing experimental platforms.

\section{REFERENCES}

Allison MA, Criqui MH and Wright CM (2004). Patterns and risk factors for systemic calcified atherosclerosis. Arterioscler. Thromb. Vasc. Biol. 24: 331-336.

Arnold MA, Kim Y, Czubryt MP, Phan D, et al. (2007). MEF2C transcription factor controls chondrocyte hypertrophy and bone development. Dev. Cell 12: 377-389.

Azevedo CF, Rochitte CE and Lima JA (2012). Coronary artery calcium score and coronary computed tomographic angiography for cardiovascular risk stratification. Arq. Bras. Cardiol. 98: 559-568.

Bas A, Lopez I, Perez J, Rodriguez M, et al. (2006). Reversibility of calcitriol-induced medial artery calcification in rats with intact renal function. J. Bone Miner. Res. 21: 484-490.

Bennett BJ, Scatena M, Kirk EA, Rattazzi M, et al. (2006). Osteoprotegerin inactivation accelerates advanced atherosclerotic lesion progression and calcification in older ApoE-/- mice. Arterioscler. Thromb. Vasc. Biol. 26: 2117-2124.

Byon CH, Javed A, Dai Q, Kappes JC, et al. (2008). Oxidative stress induces vascular calcification through modulation of the osteogenic transcription factor Runx2 by AKT signaling. J. Biol. Chem. 283: 15319-15327.

Chasseraud M, Liabeuf S, Mozar A, Mentaverri R, et al. (2011). Tumor necrosis factor-related apoptosis-inducing ligand and vascular calcification. Ther. Apher. Dial. 15: 140-146.

Coogan JS, Chan FP, Taylor CA and Feinstein JA (2011). Computational fluid dynamic simulations of aortic coarctation comparing the effects of surgical- and stent-based treatments on aortic compliance and ventricular workload. Catheter. Cardiovasc. Interv. 77: 680-691.

Cozzolino M, Dusso AS and Slatopolsky E (2001). Role of calcium-phosphate product and bone-associated proteins on vascular calcification in renal failure. J. Am. Soc. Nephrol. 12: 2511-2516.

Ioannou CV, Morel DR, Katsamouris AN, Katranitsa S, et al. (2009). Left ventricular hypertrophy induced by reduced aortic compliance. J. Vasc. Res. 46: 417-425.

Johnson K, Polewski M, van Etten D and Terkeltaub R (2005). Chondrogenesis mediated by PPi depletion promotes spontaneous aortic calcification in NPP1-/- mice. Arterioscler. Thromb. Vasc. Biol. 25: 686-691.

Kapustin AN, Davies JD, Reynolds JL, McNair R, et al. (2011). Calcium regulates key components of vascular smooth muscle cell-derived matrix vesicles to enhance mineralization. Circ. Res. 109: e1-12.

Kuroda C, Kubota S, Kawata K, Aoyama E, et al. (2008). Distribution, gene expression, and functional role of EphA4 during ossification. Biochem. Biophys. Res. Commun. 374: 22-27. 
Li W, Zara JN, Siu RK, Lee M, et al. (2011). Nell-1 enhances bone regeneration in a rat critical-sized femoral segmental defect model. Plast. Reconstr. Surg. 127: 580-587.

Liyang W, Hinoi E, Takemori A, Takarada T, et al. (2005) Abolition of chondral mineralization by group III metabotropic glutamate receptors expressed in rodent cartilage. Br. J. Pharmacol. 146: 732-743.

Morony S, Tintut Y, Zhang Z, Cattley RC, et al. (2008). Osteoprotegerin inhibits vascular calcification without affecting atherosclerosis in ldlr(-/-) mice. Circulation 117: 411-420.

Okamoto H, Matsumi Y, Hoshikawa Y, Takubo K, et al. (2012). Involvement of microRNAs in regulation of osteoblastic differentiation in mouse induced pluripotent stem cells. PLoS One 7: e43800.

Okuno S, Ishimura E, Kitatani K, Fujino Y, et al. (2007). Presence of abdominal aortic calcification is significantly associated with all-cause and cardiovascular mortality in maintenance hemodialysis patients. Am. J. Kidney Dis. 49: 417-425.

Proudfoot D, Skepper JN, Hegyi L, Bennett MR, et al. (2000). Apoptosis regulates human vascular calcification in vitro: evidence for initiation of vascular calcification by apoptotic bodies. Circ. Res. 87: 1055-1062.

Qian ZR, Sano T, Yoshimoto K, Asa SL, et al. (2007). Tumor-specific downregulation and methylation of the CDH13 (H-cadherin) and CDH1 (E-cadherin) genes correlate with aggressiveness of human pituitary adenomas. Mod. Pathol. 20: 1269-1277.

Reaven PD and Sacks J (2005). Coronary artery and abdominal aortic calcification are associated with cardiovascular disease in type 2 diabetes. Diabetologia 48: 379-385.

Reynolds JL, Joannides AJ, Skepper JN, McNair R, et al. (2004). Human vascular smooth muscle cells undergo vesiclemediated calcification in response to changes in extracellular calcium and phosphate concentrations: a potential mechanism for accelerated vascular calcification in ESRD. J. Am. Soc. Nephrol. 15: 2857-2867.

Shimizu T, Tanaka T, Iso T, Matsui H, et al. (2011). Notch signaling pathway enhances bone morphogenetic protein 2 (BMP2) responsiveness of Msx2 gene to induce osteogenic differentiation and mineralization of vascular smooth muscle cells. J. Biol. Chem. 286: 19138-19148.

Towler DA and Demer LL (2011). Thematic series on the pathobiology of vascular calcification: an introduction. Circ. Res. 108: 1378-1380.

van der Windt AE, Haak E, Kops N, Verhaar JA, et al. (2012). Inhibiting calcineurin activity under physiologic tonicity elevates anabolic but suppresses catabolic chondrocyte markers. Arthritis Rheum. 64: 1929-1939. 